http://jmscr.igmpublication.org/home/ ISSN (e)-2347-176x ISSN (p) 2455-0450

crossref DOI: https://dx.doi.org/10.18535/jmscr/v9i5.17

Journal Of Medical Science And Clinical Research

\title{
Traffic Air Pollution and Respiratory Health: A Cross-Sectional Study among Traffic Police in Dhaka City (Bangladesh)
}

Authors

Dr Shakila Yeasmin ${ }^{1}$, Dr Md. Shafiur Rahman², Dr Ayesha Haidar ${ }^{3}$, Dr Ashekur Rahman Mullick* ${ }^{4}$, Dr. Mohammad Jahid Hasan ${ }^{5}$, Dr. Md. Abdullah Saeed Khan ${ }^{6}$, Prof Dr Manzurul Haque Khan ${ }^{7}$

${ }^{1,3,4}$ Institute of Epidemiology Disease Control \& Research (IEDCR), Mohakhali, Dhaka, Bangladesh

${ }^{2}$ National Institute of Preventive and Social Medicine (NIPSOM), Dhaka, Bangladesh

${ }^{5,6}$ Pi Research Consultancy Center, Dhaka, Bangladesh

${ }^{7}$ Directorate General of Health Services (DGHS), Mohakhali, Dhaka, Bangladesh

*Corresponding Author

Dr Ashekur Rahman Mullick

\begin{abstract}
Air pollution from vehicles is the main source of pollution in capital city of Bangladesh. Road traffic has the potential to significantly increase emissions of pollutants such as carbon monoxide, oxides of nitrogen, particulate matter, and hydrocarbons. These pollutants can induce harmful effects on health. Road traffic exposes traffic police to the detrimental effects of air pollutants on respiratory health. This study determined the frequency of chronic respiratory illnesses and its related factors among traffic police in Dhaka, Bangladesh. This study had a cross-sectional design conducted in a total of 384 traffic polices in different traffic zone of Dhaka city, the capital of Bangladesh. A questionnaire was used to inquire about socio-economic characteristics, occupational factors and respiratory health problems of traffic polices. According to the present study, most the respondents (84.4\%) had respiratory problems and among them cough problem are most common (31.2.1\%) followed by phlegm problem (27.6\%), whistling problem (15.4\%) when getting cold, and breathlessness when walking $(4.4 \%)$ respectively. About $3.1 \%$ were suffering from asthma and among them $2.1 \%$ had been suffering from asthma for less than 15 years. About $9.1 \%$ cases there had a history of parental lung diseases and lung cancer are the most common (1.3\%). Among the Safe PM 2.5 status only $75.9 \%$ have respiratory problems and $95.2 \%$ having respiratory problems were in unhealthy PM2.5 status. And it is also shown that there was significant association between respiratory problems and PM2.5 status. Among the Safe PM 10 status $70.6 \%$ have respiratory problems and $98.9 \%$ having respiratory problems were in unsafe PM 10status. And it is also shown that there was significant association between respiratory problems and PM 10 status. The respiratory symptoms and illnesses observed among traffic police are associated with their exposure to air pollutants from road traffic.
\end{abstract}

Keywords: Traffic Air Pollution, Respiratory Health, Traffic police.

\section{Introduction}

Air pollution from vehicles is the main source of pollution in capital city of Bangladesh ${ }^{1}$. Road traffic has the potential to significantly increase emissions of pollutants such as carbon monoxide, oxides of nitrogen, particulate matter, and hydrocarbons. 
These pollutants can induce harmful effects on health $^{2-5}$. Inhalation represents the fundamental mechanism of exposure to pollutants in humans ${ }^{6-8}$. Consequently, the respiratory system becomes a primary target of the adverse effects of air pollution ${ }^{9}$. Chronic respiratory diseases can have environmental causes such as exposure to air pollution $^{10}$.

Chronic respiratory diseases are affecting more and more people in the world. The WHO has estimated 235 million people with asthma and 64 million people with COPD worldwide ${ }^{10-12}$. Many studies have shown that some people are more exposed than others to air pollution due to their professional activity $^{6}$. Traffic polices are exposed to large quantities of ambient air pollutants when they are on duty in different traffic zone of Dhaka city. In Africa, unlike developed countries, little research has been done on the respiratory health of workers who are highly exposed to air pollution from cars. These studies were largely conducted among traffic police $^{13,14}$. The purpose of this study is to obtain data on respiratory health status of traffic polices in order to advocate and adopt targeted strategies to protect them and the population from the deleterious effects of air pollution from road traffic. This study aimed to assess the respiratory health of traffic polices exposed to chronic air pollution in Dhaka city.

\section{Materials and Methodology}

This Cross sectional study was conducted from $1^{\text {st }}$ January to $31^{\text {st }}$ December, 2018 at the different traffic zone of Dhaka city (east/west/south/north) among 384 traffic polices who were selected purposively. The traffic police who have been working for minimum 2 year were included for this study and traffic police with known respiratory deformities were excluded.

A purposive sampling technique was used and data were collected through face to face interview using a semi structured questionnaire (close ended). It was designed on the basis of American Thoracic Society (ATS) guideline European committee of Respiratory Health survey questionnaire (ECRSH).
The interview of the traffic police was arranged according to their work schedule. Before starting the interview informed written consent was taken from each traffic police and individual information was recorded on a separate questionnaire for each.

Collected data were checked edited and entered the coded questionnaire in SPSS 23 version for analysis.

\section{Results}

In this study we have 384 participants. Mean age was 39.03( \pm 8.33$)$ years. Out of 384 respondents 352 $(91.7 \%)$ were Muslim and $31(8.1 \%)$ were Hindu. About 195 (50.8\%) participants have completed secondary level of education, $108(28.1 \%)$ have completed higher secondary, 81 (21.1\%) have completed higher education like BA, MA etc. Average monthly income of the respondents was BDT 31840.89 ( \pm 6102.79$) .193(50 \%)$ respondents have smoking habit (Table 01).

According to the present study, most the respondents $(84.4 \%)$ had respiratory problems and among them cough problem are most common (31.2.1\%) followed by phlegm problem (27.6\%), whistling problem $(15.4 \%)$ when getting cold, and breathlessness when walking $(4.4 \%)$ respectively. (Table 02).

About $3.1 \%$ were suffering from asthma and among them $2.1 \%$ had been suffering from asthma for less than 15 years. About $9.1 \%$ cases there had a history of parental lung diseases and lung cancer are the most common (1.3\%).

Among the Safe PM 2.5 status only $75.9 \%$ have respiratory problems and $95.2 \%$ having respiratory problems were in unhealthy PM2.5status. And it is also shown that there was significant association between respiratory problems and PM2.5 status

Among the Safe PM 10 status $70.6 \%$ have respiratory problems and $98.9 \%$ having respiratory problems were in unsafe PM 10status. And it is also shown that there was significant association between respiratory problems and PM 10 status (Table 02). . 
Table 1: Presence of respiratory problems in relation to different factors

\begin{tabular}{llrc}
\hline Socio-demography & Category & f $(\%)$ & Mean $( \pm$ SD $)$ \\
\hline \multirow{4}{*}{ Age } & $20-29$ years & $49(89.1 \%)$ & \\
& $30-39$ years & $95(78.5 \%)$ & 0.139 \\
& 40-49 years & $150(86.7 \%)$ & \\
\hline \multirow{2}{*}{ Smoking status } & $>49$ years & $30(85.7 \%)$ & \\
\hline \multirow{2}{*}{ Duration of employment } & Yes & $165(85.5 \%)$ & 0.554 \\
& No & $159(83.2 \%)$ & \\
\hline \multirow{2}{*}{ PM 2.5 status } & $<10$ years & $109(79.6 \%)$ & \multirow{2}{*}{0.053} \\
\cline { 2 - 4 } PM 10 status & Safe $(<100 \mathrm{ug} / \mathrm{m} 3)$ & $164(75.0 \%)$ & 0.001 \\
& Unsafe $(>100 \mathrm{ug} / \mathrm{m} 3)$ & $160(95.2 \%)$ & \\
\hline
\end{tabular}

Table 2: Distribution of respondents according to different respiratory health problems

\begin{tabular}{lcc}
\hline Variables & Frequency & Percent \\
\hline Cough & 120 & 31.2 \\
Phlegm & 106 & 27.6 \\
Whistling & 70 & 18.3 \\
Breathless when walking & 17 & 4.4 \\
\hline
\end{tabular}

\section{Discussions}

The relationship between occupation and occupational pulmonary contaminants and respiratory health problems have been studied since earlier. But in Bangladesh there is very limited study about respiratory health problems among traffic police. This study was designed to explore the prevalence of respiratory health problems among traffic police in Dhaka city. This study showed that respiratory problems among the traffic police of 20-29 years of age (89.1\%), 30-39 (78.5\%), $40-49(86.7 \%)$ and $>49(85.7 \%)$ years. Age 30-39 $(78.5 \%)$ traffic police had less respiratory problems. The findings indicated that the reasons for higher respiratory problems amongst young study subjects may include lack of information, lack of training, lack of supervision, lack of experience on the job, lack of knowledge and skill. Older workers had lower chance of injury which may be because they had more work experience but on the other hand, it was also possible that because of their seniority, they were less exposed to the occupational hazards in the workplace in their actual assignments. Most of the study found that having respiratory problems higher among the older age group ${ }^{15}$.

The respondents having respiratory problems was found higher among the smoker than the nonsmoker. It's because the smoking causes respiratory problems and reduction of lung capacity. The same finding also found in several study ${ }^{16}$.

The percentage of respiratory health problems was $79.6 \%$ among the respondent who were employed in Dhaka city for less than 10 yrs. followed by $87 \%$ of the respondent who were employed in Dhaka city for more than $10 \mathrm{yrs}$. That means the respondent are exposed to air pollution for more than 10 years had much respiratory problems. The Same type findings was also found in several study ${ }^{17}$.

Different studies showed that where the level of PM10 was increased there was presence of different respiratory health problems and also shown that there was significant association between them. And also, in present study it was estimated that where PM2.5 and PM10 level increased there was presence of different respiratory health problems and also in unhealthy PM2.5 and PM10 level there was high prevalence of respiratory problems. And there was significant association ${ }^{18-20}$.

\section{Conclusions}

This cross-sectional study was conducted among traffic police in different traffic zone of Dhaka city to find out the proportion of traffic police having respiratory health problems. Among total respondent $5 \%$ respondent had respiratory problems. The percentage of respiratory health problems was 
higher among the respondent who were appointed as traffic police in Dhaka city for more than 10 yrs. The respiratory health problems were higher among the respondent who did not smoke. Among the ways, the use of mask and regular health checkup can prevent the effects of air pollution. The majority of the traffic police did not use masks during duty hours and had rotation in duty areas. The level of knowledge among the traffic police is adequate, but the level of practice on prevention of respiratory health problems is not satisfactory. Association of level of practice was observed with working experience but not with education of the traffic police in Dhaka. It is the responsibility of the government and concerned authorities to deal with the issues and derive effective and sustainable solutions to ensure better health of traffic police in the city.

\section{Acknowledgments}

Author thanks to the all traffic police who provides their consent and take participation within their busy schedule. The authors also thankful to DMP commissioner for his co-operation and suggestion.

\section{Declarations}

Funding: This research protocol was self-funded.

Conflict of Interest: No competing interests relevant to this study to disclose for all authors. Full forms submitted and on file for all authors.

Ethical Approval: The objectives and importance of the research were explained to all participants prior to recruitment. Participation in the study was voluntary. The confidentiality of the participants was maintained, and written informed consent as well as ascent was obtained from all participants. The study was approved by the Institutional Review Board (IRB) of the National Institute of Preventive and Social Medicine (NIPSOM) and obtained an ethical clearance waiver from same source.

\section{References}

1. Ahmmed, K.M.T. and Begum, D.A., (2010) Air pollution aspects of Dhaka City.Proc. Of
International Conference on Environmental Aspects of Bangladesh, Japan. 2290(75).

2. Ahmed, S., Akter, Q.S., Eva, H. and Bhowmik, M., (2016) Effect of air pollution on FVC, FEV1 and FEV1/FVC\% of the traffic policemen in Dhaka city. Journal of Bangladesh Society of Physiologis. 11(2), 39-42.

3. Aït-Khaled, N., Enarson, D. and Bousquet, J (2001) chronic respiratory diseases in developing countries: the burden and strategies for prevention and management. Bulletin of the World Health Organization. 79,971-979.

4. American Thoracic Society, (1979) ATS statement-Snowbird workshop on standardization of spirometry. Am Rev Respir Dis. 119,831-838

5. Aryal Bhandari, A., Gautam, R. and Bhandari, S., (2015). Knowledge and practice on prevention of respiratory health problems among traffic police in Kathmandu, Nepal. International scholarly research notices.

6. Bangladesh Road Traffic Authority, (2010) Number of Vehicle Change in Dhaka. Up to 2009(BRTA, 2010).

Available from:

https://www.researchgate.net/.../Number-ofvehicle-cha

7. Burgaz, S., Demircigil, G.C., Karahalil, B. and Karakaya, A.E., (2002). Chromosomal damage in peripheral blood lymphocytes of traffic policemen and taxi drivers exposed to urban air pollution. Chemosphere.47 (1), 5764.

8. Chhabra, S.K., (2014). Interpretation of spirometry: Selection of predicted values and defining abnormality. Indian J Chest Dis Allied Sci. 57, 91-105.

9. Crebelli, R., Tomei, F., Zijno, A., Ghittori, S., Imbriani, M., Gamberale, D., Martini, A. and Carere, A., (2001). Exposure to benzene in urban workers: environmental and biological monitoring of traffic police in 
Rome. Occupational and environmental medicine. 58(3), 165-171.

Available from: http://oem.bmj.com/

10. Daily star, (22nd April, 2108). Respiratory Disease skyrocketing in Bangladesh.

11. Dr. Colin Tidy, (2016) Spirometry. Patient. Available from: https://patient.info

12. Dutta, T. and Pal, G., (2010). Pulmonary function test in traffic police personnel in Pondicherry. Indian J Physiol Pharmacol, 54(4), 329-336.

13. Estévez-García, J.A., Rojas-Roa, N.Y. and Rodríguez-Pulido, A.I., (2013). Occupational exposure to air pollutants: particulate matter and respiratory symptoms affecting traffic-police in Bogotá. Revista de salud publica. 15,870-885.

14. Gupta, S., Mittal, Kumar, A. and Singh, K.D., (2011). Respiratory effects of air pollutants among nonsmoking traffic policemen of Patiala, India. Lung India: official organ of Indian Chest Societ., 28(4), .253.

15. Health line, (2017).Spirometry: What to expect and how to interpret your result.

Available from:

https://www.healthline.com/health/spiromete $\mathrm{r}$

16. Ingle, S.T., Pachpande, B.G., Wagh, N.D., Patel, V.S. and Attarde, S.B., (2005). Exposure to vehicular pollution and respiratory impairment of traffic policemen in Jalgaon City, India. Industrial health. 43(4), 656-662.

17. Künzli, N., Kaiser, R., Medina, S., Studnicka, M., Chanel, O., Filliger, P., Herry, M., Horak Jr, F., Puybonnieux-Texier, V., Quénel, P. and Schneider, J., (2000). Publichealth impact of outdoor and traffic-related air pollution: a European assessment. The Lancet, 356(9232), 795-801.

http://dx.doi.org/10.1016/S0140-

6736(00)02653-2
18. Krzyzanowski M, Cohen A (2008). Update of WHO air quality guidelines. Air QualAtmos Health. Available from: www.euro.who.int.

19. MacIntyre, N.R., (2009). Spirometry for the diagnosis and management of chronic obstructive pulmonary disease. Respiratory care. 54(8), 1050-1057.

20. Maddur, N.K., Reddy, S., Sowmya, J. and Waghray, P., (2016). Respiratory effects of air pollutants among non-smoking traffic policemen: An analytical cross sectional study. International Archives of Integrated Medicine. 3(5), 8-13. 